\title{
Refractory bile leak with biliocutaneous fistula treated by endobiliary coil placement
}

A 38-year-old woman with abdominal gunshot injury underwent hepatorrhaphy, gastrorrhaphy, splenectomy, and hemicolectomy for severe liver, gastric, splenic, and colonic injury. On postoperative day 10, Gastroenterology was consulted for evaluation of a bile leak, after bilious drainage was seen in the perihepatic intra-abdominal drain.

Abdominal computed tomography scan showed a fluid collection around the right hepatic lobe. Endoscopic retrograde cholangiopancreatography (ERCP), performed for evaluation of the bile leak, showed contrast leakage from a branch of the right hepatic duct, for which a biliary stent was placed.

After prolonged hospitalization, repeat ERCP was performed on an outpatient basis at 3 and 6 months. During this period, there was persistent bile leakage from a branch of the right hepatic duct despite biliary stent exchanges ( $\mathbf{F i g . 1}$ ). In the interim, the patient also developed a biliocutaneous fistula, with bilious discharge from the skin over the right upper quadrant.

A decision was made to proceed with intrabiliary coil placement [1] after consulting with Hepatobiliary Surgery.

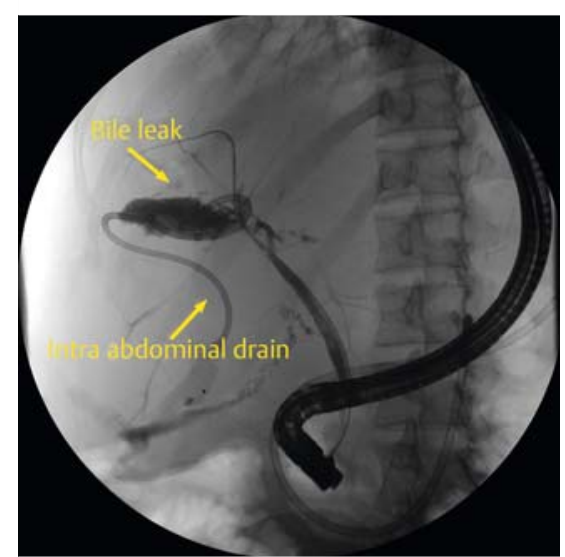

- Fig. 1 Endoscopic retrograde cholangiopancreatography showed contrast leakage from a branch of the right hepatic duct.
Platinum embolization coils (Tornado; Cook Medical, Bloomington, Indiana, USA), 0.035 inches in diameter and $4.1 \mathrm{~cm}$ in length, were backloaded into a long-wire $4.4 \mathrm{Fr}$ sphincterotome. The sphincterotome was advanced to the site of the biliary leak, and two coils were deployed by using a 0.035 -inch guidewire to push them through the sphincterotome. After deployment, the coils assumed their circular shape, confirming coil deployment at the site of duct disruption ( $\vee$ Video 1 ). There was resolution of the biliocutaneous fistula within 24 hours. The patient was given oral ciprofloxacin for a week after ERCP. There was no fever or abdominal pain at 2 month follow-up, indicating successful treatment of refractory bile leak by endobiliary coil placement.

This case demonstrates an off-label use of platinum embolization coils, which are primarily used by interventional radiologists for endovascular use. Endobiliary coil placement is an effective strategy for managing difficult and refractory bile leaks arising from liver trauma.

Endoscopy_UCTN_Code_TTT_1AR_2AG
Competing interests

None

The Authors

Tejas Kirtane ${ }^{1}$, Deepinder Goyal ${ }^{1}$, Erik Rahimi ${ }^{1}$, Atilla Ertan ${ }^{1,2}$, John S. Bynon ${ }^{3}$, Nirav Thosani ${ }^{1}$

1 Department of Internal Medicine, Division of Gastroenterology, Hepatology and Nutrition, University of Texas Health Science Center at Houston, Houston, Texas, United States

2 Memorial Hermann Medical Center, Ertan Digestive Disease Center, Houston, Texas, United States

3 Surgery-Liver Transplant, University of Texas Health Science Center at Houston, Houston, Texas, United States

Corresponding author

\section{Tejas Kirtane, MD}

Department of Internal Medicine, Division of Gastroenterology, Hepatology and Nutrition, University of Texas Health Science Center at Houston, 6411 Fannin St, MSB 2.323,

Houston, TX, USA 77030

Fax: +1-713-5006699

tejaskirtane84@gmail.com

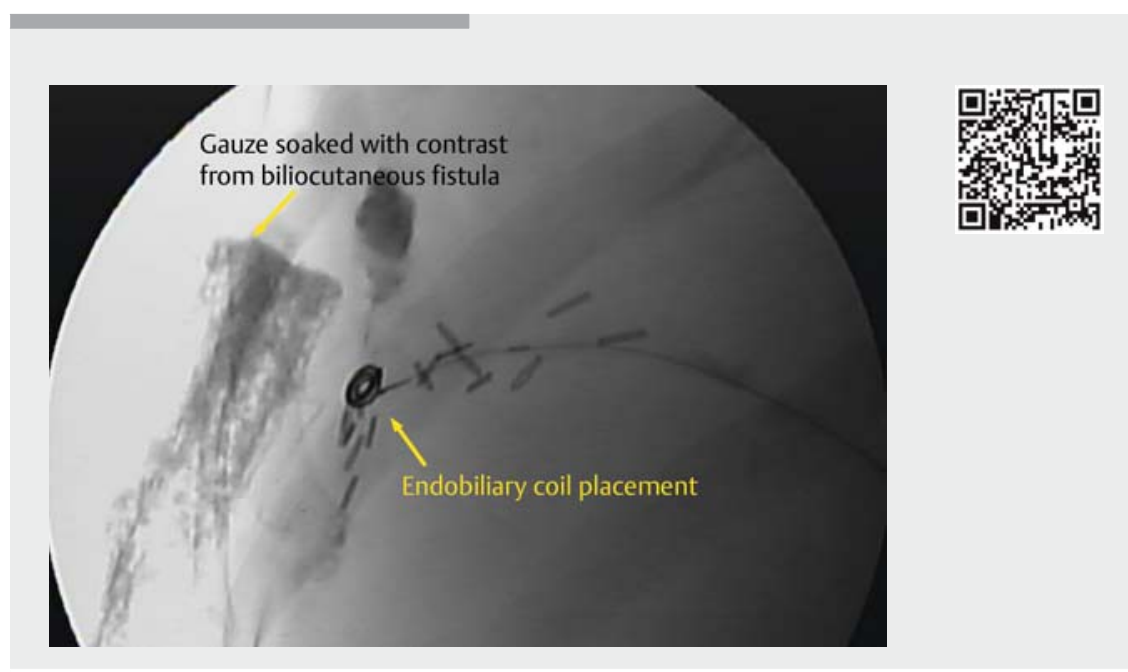

$\checkmark$ Video 1 Refractory bile leak with biliocutaneous fistula treated by endobiliary coil placement. 
[1] Schelhammer F, Dahl SV, Heintges T et al. A multimodal approach in coil embolization of a bile leak following cholecystectomy. Cardiovasc Intervent Radiol 2007; 30: 529-530

\section{Bibliography}

DOI https://doi.org/10.1055/s-0043-119345

Published online: 25.9.2017

Endoscopy 2017; 49: 1280-1281

(C) Georg Thieme Verlag KG

Stuttgart · New York

ISSN 0013-726X
ENDOSCOPY E-VIDEOS

https:/|eref.thieme.de/e-videos

口否回 Endoscopy E-Videos is a free 然故 access online section, reporting 回和: on interesting cases and new techniques in gastroenterological endoscopy. All papers include a high quality video and all contributions are freely accessible online.

This section has its own submission website at

https://mc.manuscriptcentral.com/e-videos 